\title{
Task Allocation of Intelligent Warehouse Picking System based on Multi-robot Coalition
}

\author{
Fei Xue*, Hengliang Tang, Qinghua Su, and Tao Li \\ School of Information \\ Beijing Wuzi University \\ Tongzhou, Beijing, 101149, China \\ [e-mail: xuefei2004@126.com; hltangbwu@126.com; suqinghuabwu@163.com; liutaobwu@sohu.com] \\ *Corresponding author: Fei Xue
}

\begin{abstract}
In intelligent warehouse picking system, the allocation of tasks has an important influence on the efficiency of the whole system because of the large number of robots and orders. The paper proposes a method to solve the task allocation problem that multi-robot task allocation problem is transformed into transportation problem to find a collision-free task allocation scheme and then improve the capability of task processing. The task time window and the power consumption of multi-robot (driving distance) are regarded as the utility function and the maximized utility function is the objective function. Then an integer programming formulation is constructed considering the number of task assignment on an agent according to their battery consumption restriction. The problem of task allocation is solved by table working method. Finally, simulation modeling of the methods based on table working method is carried out. Results show that the method has good performance and can improve the efficiency of the task execution.
\end{abstract}

Keywords: Multi-robot, transportation problem, task allocation, time window, table working method 


\section{Introduction}

The cost of order picking accounts for 55 percent of the total warehouse logistics cost in warehouse logistics system [1][2], so it is particularly prominent that efficient picking has an important influence on the efficiency of the whole system. Most current order picking systems utilize either the "picker-to-parts" or "parts-to-picker" mode. In picker-to-parts order picking, a warehouse picker selects goods from the shelf based on the released order. However, high-capacity automated warehouses usually utilize the parts-to-picker mode, in which logistics robots are used to move goods from the shelf to the location of the picker, who then selects and places them in the appropriate boxes. Amazon' s Kiva is an example of a system that successfully utilizes the parts-to-picker model [3][4]. Multi-robot is a kind of intelligent logistics equipment which can be self-navigated, self-driving and flexible scheduling to provide a new "parts-to-picker" picking model. The parallel and efficient operation mode of multi-robot and low-cost robot productions make robots used in various areas such as environmental monitoring [5], warehouse automation [6], search and rescue [7], etc.

Previous studies on the optimization of large-scale order-picking systems that utilize logistic multi-robots [8][9] mainly focused on the warehouse layout, order batching, task assignment, and path planning. Among the hot topic in the study of multi-robot, the problems such as the task assignment, the path optimization of multi-robot, the coordination control of multi-robot, etc, are caught a great deal of attention. The multi-robot task allocation (MRTA) problem [10][11] refers to the assigning of a series of tasks to a series of robots with certain constraints, such that together they can complete a set of goals (e.g., the MINISUM, MINIMAX, and MINIAVE goals proposed by Tovey et al. [12]). To solve the problem of task allocation, scholars and experts propose mathematical models and solving methods. Task allocation problem can be seen as a combination optimization problem [13-17], a linear programming problem [18-22], a multiple traveling salesman problem [23], an optimization problem [24-29], etc. The methods of solving task allocation problem [30][31] mainly include the followings:

(1) swarm intelligent algorithms [32-38]. Cui [39][40] applied bat algorithm and its variants to improve the malicious code variants detection model and to optimize the cluster head node selection of LEACH protocol. Their models are all effective and achieved good results. Gheraibia [41] proposes an ant colony algorithm with a guided search function to solve task allocation problems and this method can accelerate the convergence speed. For dynamic task allocation problems, Nedjah [42] uses a improved particle swarm algorithm to solve the distributed tasks. Neshat [43] proposes to solve task allocation problems by fish school algorithms.

(2) market-based approaches. Market-based approaches [44][45] apply the idea of resource allocation on task allocation problems, which have better robustness and flexibility. Z.Robert [46] firstly applies the market-based approach to the dynamic task allocation problems, which can solve the smaller dynamic task allocation problem. Elango et al. [47] proposed using the K-means clustering algorithm and auction mechanism to solve the two-objective task allocation model considering both the total travel distance and the robot's efficiency. 
(3) other task allocation approaches. Nagarajan et al. [48] constructed a multi-agent system framework and designed a heuristic algorithm based to solve the MRTA problem, aiming at minimizing the turnaround time of the robot. There are other methods to solve task allocation problems such as accurate algorithms, Hungarian algorithms, graphical methods, quadratic programming algorithms, etc. However, the literature shows that research on the MRTA problem is mainly carried out from the perspectives of the task and robot, whereas the important picking time constraint of the task is ignored.

According to review a number of related studies about task allocations in the past few years, task allocation is a hot issue. In intelligent warehouse environment, it is difficult to provide formal performance guarantees due to the large-scale robots and tasks. In the paper, firstly, a linear programming mathematical model was established with regard to each task time window and the robot power consuming and each robot execution capability. Then, referring to the solution of transportation problem, a fast solution method was put forward and provided formal performance guarantees.

The rest of the paper is organized as follows. In the second part, the analysis of operating procedure of the intelligent warehouse system based on multi-robot is given. In the third part, a mathematical model of task allocation is established. Then, an improved table working method is put forward to solve this model. In the fifth part, simulation is carried out and results show that the method is valid and rational. Finally, some conclusions are reached and the prospect is given.

\section{System Description}

E-commerce tasks are usually very varied, small-batch, and high in frequency. Wave-picking is the assignment of the number of tasks to be picked within a certain period after their arrival, with the purpose of improving the picking efficiency [49]. The wave-picking method was adopted in the present study, with the tasks in the task pool continually arriving at places from where a certain quantity is removed with the arrival of subsequent tasks. In this method, the number of tasks in a wave is first determined, and the tasks are then divided into $h$ batches based on certain rules, and distributed to h picking stations. The tasks in the same batch are merged into a pick list with several subtasks. The subtasks are subsequently assigned to robots that perform the picking. The task batching process is illustrated in Fig. 1.

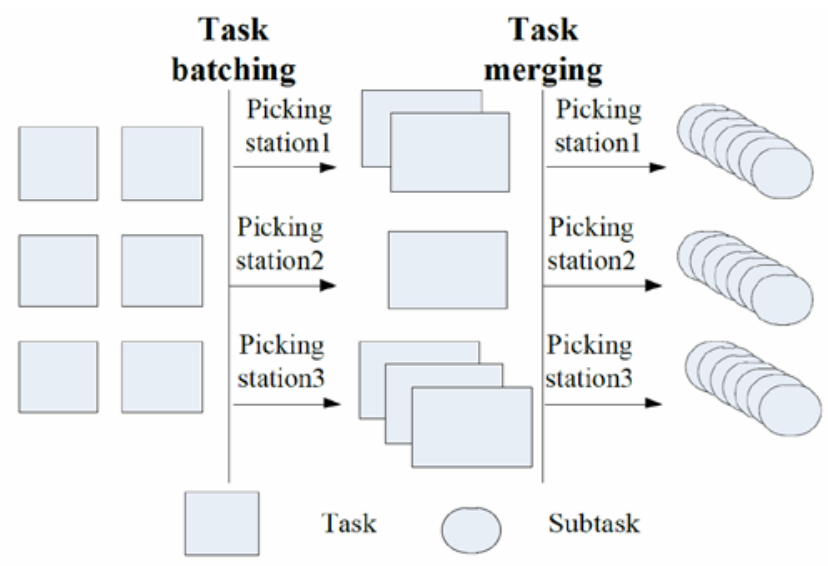

Fig. 1. Task batching process 
A large-scale logistics robot intelligent storage system is depicted in Figure 2. For a typical intelligent storage system, readers can refer to the KIVA System.[50][51] In intelligent warehouse system, there are mainly six parts, including picking stations, human operators, multi-robot, tasks, subtasks and box take away conveyor, shown in Fig. 2. After a certain amount of orders arrived, firstly, orders are integrated and decomposed into independent subtasks. Then, the subtasks are assigned to picking stations according to a special set of rules. Finally, picking stations assign independent subtasks to multi-robot who can transport the subtask to the corresponding picking station.

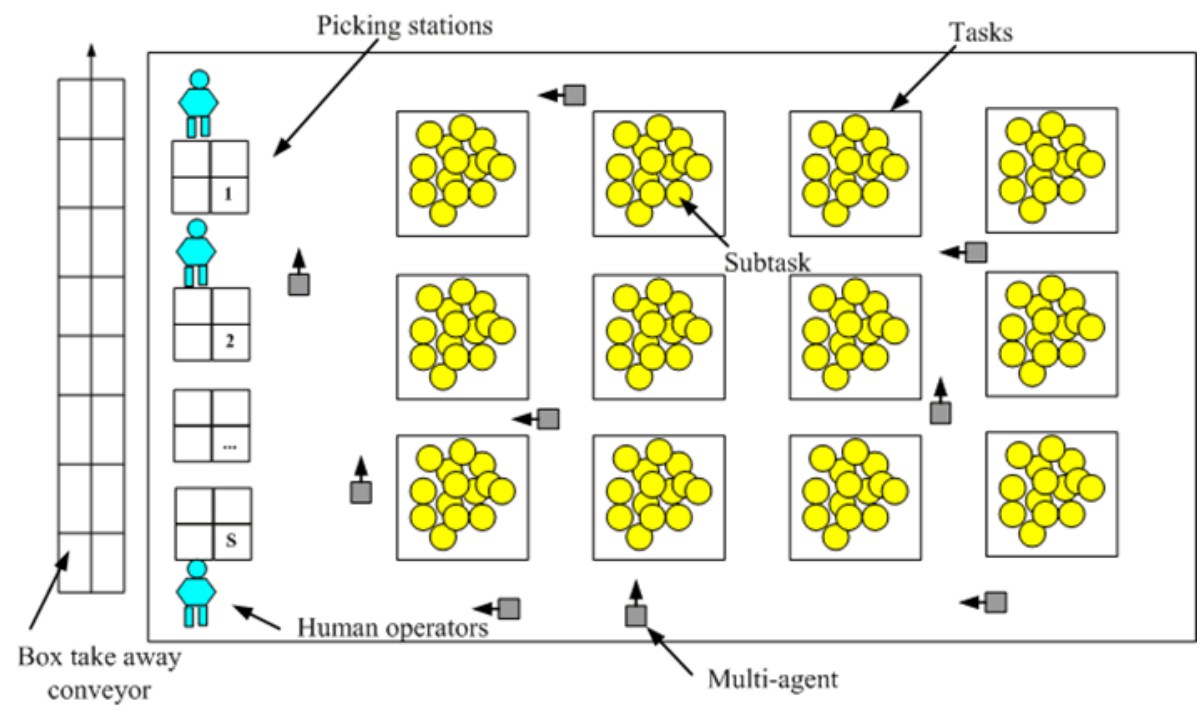

Fig. 2. Environment of the intelligent warehouse system

The components of the multi-robot task allocation system are shown in Fig. 3. In this system, it mainly contains central control unit(1), picking stations (secondary control unit)(2), storage area and multi-robot(3) and information feedback system(4).

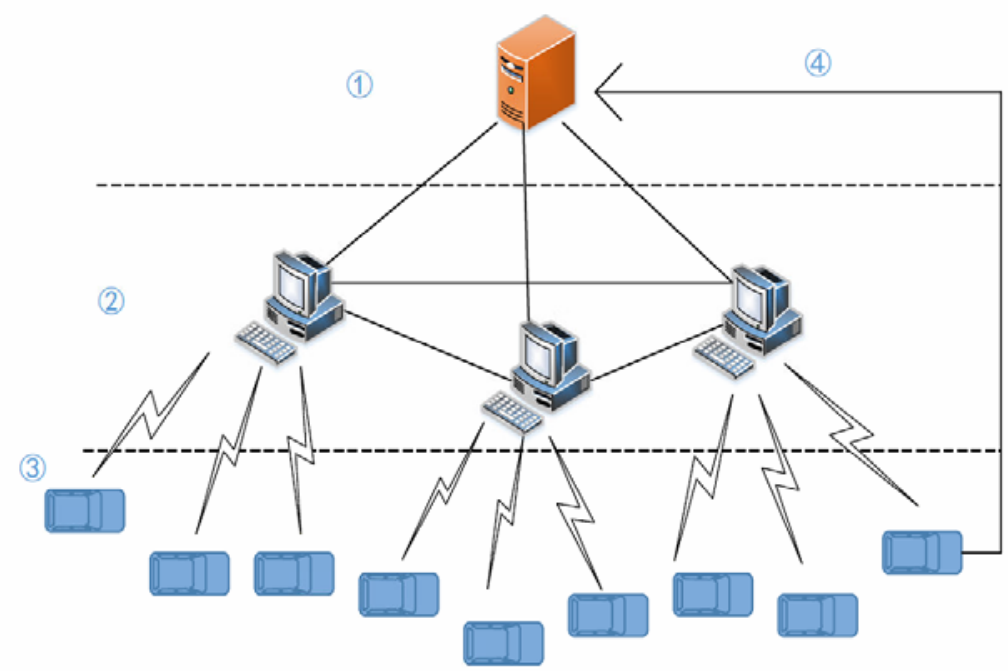

Fig. 3. Multi-robot system architecture diagram 
The central control unit bears the function to allocate orders primarily and analyze and process the data returned. The picking area includes many paratactic picking stations. Every picking station is equivalent to a secondary control unit which receives and preprocesses the orders allocated by the central control unit. Then it will allocate the processed tasks to robots and complete the consolidation of picking orders. The storage area includes multiple robots, goods shelves and goods on shelves. There are many kinds of goods stored on the shelves. Robots receive tasks from the secondary control unit and feedback the information in storage area to the central control unit, as a result, it will complete an optimal task allocation scheme without conflict.

The complexity of solving task allocation problems rises with the increased number of robots and tasks and many complex constraints are some difficulties in solving task allocation problems. Through the analysis of the operation procedure of multi-robot in intelligent warehouse system, this paper analyzes it from the following aspects. Firstly, tasks are time-bound so that tasks are completed as many as possible within the time allowed. Secondly, the loss of the robot power consumption is as small as possible and the battery consumption is considered for the number of task assignment on an robot. Finally, tasks are finished in the least time.

\section{The Description and Establishment of Mathematician Model}

Basic assumptions:

Suppose a warehousing company has $n$ multi-robot and $m$ tasks. Then, the basic assumptions are:

- Every task is made up of a series of subtasks with the same position coordinate.The shape and volume of all subtasks in the task are roughly the same.

- Subtask should be regarded as the indivisible unit, and can be executed by an robot. One shelf can store several different subtasks.

- The robot's ability to execute tasks is different according to the battery consumption of an robot. Robots have the same speed, and movement is at a constant uniform speed.

- The interactions between the robots are not considered [52] , but only the impact of the fulfillment time cost of the task on the robot.

- The size of the product from robot $i$ to task $j$ is $x_{i j}$, where $i=1,2, \ldots, n$ and $j=1,2, \ldots, m$.

- The total supply of the product from robot $i$ is $a_{i}$, where $i=1,2, \ldots, n$.

- The total demand for the product at task $\mathrm{j}$ is $b_{j}$, where $j=1,2, \ldots, m$.

- The benefit value of sending one unit of the product from robot $i$ to task $j$ is equal to $s_{i j}$, where $i=1,2, \ldots, n$ and $j=1,2, \ldots, m$.

\subsection{The Description of Mathematician Model}

The problem of multi-robot task allocation is how to allocate multiple robots to execute task and at the same time how a task can be finished by multi-robot. This kind of multi-robot -task allocation problem can be expressed in matrix : 


$$
Y=\left[\begin{array}{cccc}
\mathrm{y}_{11} & \mathrm{y}_{12} & \ldots & \mathrm{y}_{1 m} \\
\mathrm{y}_{21} & \mathrm{y}_{22} & \ldots & \mathrm{y}_{2 m} \\
\ldots & \ldots & \ldots & \ldots \\
\mathrm{y}_{n 1} & \mathrm{y}_{n 2} & \ldots & \mathrm{y}_{n m}
\end{array}\right]
$$

Each robot has a given level of supply and each task has a given level of demand. Then this allocation problem could be transformed into transportation problem. The transportation benefit value between every pair of robot and task are also given in Table 1.

Table 1. Transportation benefit value table

\begin{tabular}{c|ccccc}
\hline B1 & $\mathrm{A}_{1}$ & $\mathrm{~A}_{2}$ & $\ldots$ & $\mathrm{A}_{\mathrm{m}}$ & $\begin{array}{c}\text { The demand } \\
\text { at multi-task }\end{array}$ \\
$\mathrm{B} 2$ & $\mathrm{~s}_{11}$ & $\mathrm{~s}_{12}$ & $\ldots$ & $\mathrm{s}_{1 \mathrm{~m}}$ & $\mathrm{~b}_{1}$ \\
$\ldots$ & $\mathrm{s}_{21}$ & $\mathrm{~s}_{22}$ & $\ldots$ & $\mathrm{s}_{2 \mathrm{~m}}$ & $\mathrm{~b}_{2}$ \\
$\begin{array}{c}\text { Bn } \\
\begin{array}{c}\text { The supply } \\
\text { from } \\
\text { multi-robot }\end{array}\end{array}$ & $\ldots$ & $\ldots$ & $\cdots$ & $\ldots$ & $\ldots$ \\
\hline
\end{tabular}

\subsection{The Establishment of Mathematician Model}

This mathematician model includes the objective function and the constraints. A warehousing company has $\mathrm{n}$ multi-robot and m multi-task. For any $i$ and any $j$, the transportation benefit value per unit is $s_{i j}$, and the size of the product is $x_{i j}$. Summing over all $i$ and all $j$ now yields the overall transportation benefit value for all robot-task combinations. Then, objective function is:

$$
\max f=\sum_{i=1}^{n} \sum_{j=1}^{m} s_{i j} x_{i j}
$$

Consider robot $i$ and task $j$. The total supply of the product cannot exceed $b_{j}$, and the total demand for the product should not be less than $a_{i}$. Then, constraints is:

$$
\begin{gathered}
\sum_{i=1}^{n} x_{i j} \leq \mathrm{b}_{j} \quad(j=1,2, \ldots, m) \\
\sum_{j=1}^{m} x_{i j} \geq \mathrm{a}_{i} \quad(i=1,2, \ldots, n) \\
x_{i j} \geq 0 \quad(i=1,2, \ldots, n, j=1,2, \ldots, m)
\end{gathered}
$$

\subsection{The Establishment of Benefit Function}

We take the actual task allocation circumstance into consideration. First, the order is preprocessed that the same type of goods puts in together. Then, the same type of goods is centralized processing. The factors affecting benefit function mainly includes the following two [53]: 


\section{(1) the power consumption costs}

The power consumption costs is related with distance between robot and task. The location of each robot can be measured, and the location of each task is known. So, the distance between robot $i$ and task $j$ can be expressed as the following form:

$$
D_{i j}=\sqrt{\left(x_{i}-x_{j}\right)^{2}+\left(y_{i}-y_{j}\right)^{2}}
$$

So, the benefit function about the power consumption costs can be expressed as the following form:

$$
s_{1}=-F D_{i j}
$$

Where $F$ is per unit the energy costs.

\section{(2) time window}

The time-consuming of the task is mainly related with the speed of the robot $i$ and the distance between the robot $i$ and the task $j$. We assume that multi-robot moves with $a$ constant velocity $(v)$. Then, the time-consuming can be expressed as the following form:

$$
t_{i j}=D_{i j} / v
$$

And the benefit function about the time-consuming can be expressed as the following form:

$$
s_{2}=e-\alpha t_{i j}
$$

Where $\alpha$ is the penalty coefficient.

We take the time window into consideration. The task $j$ can be finished as long as the time-consuming doesn't exceed the longest time $\left(t_{\text {end }}\right)$. Then, constraints can be expressed as the following form:

$$
u_{j}=\left\{\begin{array}{rr}
1 & t \leq t_{\text {end }} \\
0 & \text { otherwise }
\end{array}\right.
$$

And the benefit function about the time window can be expressed as the following form:

$$
s_{3}=u_{j} e-\alpha t_{i j}
$$

We can get the total benefit function by formula(6)and(10):

$$
s_{i j}=s_{1}+s_{3}=u_{j} e-\alpha t_{i j}-F D_{i j}
$$

\section{The Steps of the Task Allocation Method Based on Table Working Method}

Based on the actual operation of logistics warehouse storage systems and studies presented in the literature, each robot has a given level of supply and each task has a given 
level of demand. Then this allocation problem could be transformed into transportation problem. In this paper, we used the table working method to analyze the task allocation problem of multi-robot. The steps of the multi-robot task allocation based on table working method are as follows.

Step1: Parameter initialization: set the initial value of robot number $n$, the initial value of task number $m$, the task time windows $t$, the speed of multi-robot value $v$, the penalty coefficient $\alpha$, the per unit the energy cost $F$.

Step2: Find out the initial basic feasible solution: the number of digital lattice (basic variable) is $m+n-1$.

Step3: Solve the test number ( $\delta$ ) of non-basic variable (space).

Step4: Determine the basic variable in simplex, if $\min \left\{\delta_{\mathrm{ij}} \mid \delta_{\mathrm{ij}}\langle 0\}=\delta_{l k}\right.$, then $x_{i j}$ is as the basic variable in simplex.

Step5: Determine the basic variable out simplex, and find out the closed loops of the basic variable in simplex.

Step6: Adjusted the task allocation scheme by closed-loop method.

Step7: Repeat Step2 to Step5 until the optimal assignment scheme is received.

\section{Simulation Analyses}

An e-commerce enterprise A was used to assess the validity of the proposed task allocation model and algorithm. The tasks received by the company A are highly varied, small-batch, and of high frequency. The company utilizes a large-scale logistic multi-robot intelligent warehouse system with a total storage area of 6000 square meters divided into four identical zones. There are 800 shelves and 2000 categories of goods per zone, with each shelf holding 10-15 subtasks.

To prove the reliability of the model, we calculate the model by LINGO11 software. As an actual example, suppose we are given: the number of multi-robot is 10 and the number of multi-task is 20; the longest time of each task is 30min;the moving velocity of multi-robot is $2 \mathrm{~m} / \mathrm{s}$; the penalty coefficient $(\alpha)$ is 0.1 ; the per unit the energy costs $(F)$ is $10^{-4}$. The basic data is shown as following Table 2, Table 3 and Table 4.

Table 2. Parameter description and values

\begin{tabular}{ccc}
\hline Symbols & Description & Value \\
\hline$|R|$ & Number of robots & 10 \\
$|\mathrm{~B}|$ & Number of tasks & 20 \\
$v$ & Moving velocity of mult-robot & 2 \\
$t^{\prime}$ & th/s) & 30 \\
$\alpha$ & the longest time of each task (min) & 0.1 \\
$F$ & the per unit the energy costs & $10^{-4}$ \\
\hline
\end{tabular}


Table 3. The description of multi-robot

\begin{tabular}{c|cccccccccc}
\hline number & $\mathrm{A}_{1}$ & $\mathrm{~A}_{2}$ & $\mathrm{~A}_{3}$ & $\mathrm{~A}_{4}$ & $\mathrm{~A}_{5}$ & $\mathrm{~A}_{6}$ & $\mathrm{~A}_{7}$ & $\mathrm{~A}_{8}$ & $\mathrm{~A}_{9}$ & $\mathrm{~A}_{10}$ \\
\hline Supply & 340 & 320 & 330 & 310 & 290 & 270 & 350 & 340 & 360 & 290 \\
$\mathrm{x}$ & 60 & 40 & 18 & 60 & 50 & 5 & 38 & 28 & 18 & 6 \\
$\mathrm{y}$ & 60 & 70 & 25 & 38 & 90 & 82 & 58 & 83 & 78 & 94 \\
\hline
\end{tabular}

Table 4. The description of multi-task

\begin{tabular}{ccc}
\hline number & demand & position coordinates \\
\hline $\mathrm{B}_{1}$ & 230 & $(65,26)$ \\
$\mathrm{B}_{2}$ & 200 & $(50,25)$ \\
$\mathrm{B}_{3}$ & 180 & $(25,45)$ \\
$\mathrm{B}_{4}$ & 90 & $(37,42)$ \\
$\mathrm{B}_{5}$ & 70 & $(25,40)$ \\
$\mathrm{B}_{6}$ & 110 & $(37,42)$ \\
$\mathrm{B}_{7}$ & 60 & $(25,40)$ \\
$\mathrm{B}_{8}$ & 80 & $(30,92)$ \\
$\mathrm{B}_{9}$ & 120 & $(5,39)$ \\
$\mathrm{B}_{10}$ & 210 & $(25,28)$ \\
$\mathrm{B}_{11}$ & 110 & $(65,10)$ \\
$\mathrm{B}_{12}$ & 150 & $(10,15)$ \\
$\mathrm{B}_{13}$ & 210 & $(53,64)$ \\
$\mathrm{B}_{14}$ & 360 & $(72,50)$ \\
$\mathrm{B}_{15}$ & 70 & $(32,43)$ \\
$\mathrm{B}_{16}$ & 50 & $(55,60)$ \\
$\mathrm{B}_{17}$ & 310 & $(42,64)$ \\
$\mathrm{B}_{18}$ & 160 & $(38,45)$ \\
$\mathrm{B}_{19}$ & 270 & $(36,43)$ \\
$\mathrm{B}_{20}$ & 160 & $(28,37)$ \\
\hline
\end{tabular}

The benefit value can be calculated by basic data and the formula (5),(7),(11). 
Table 5. The benefit value

\begin{tabular}{l|llllllllll}
\hline agent & & & & & & & & & & \\
\hline & & & & & & & & \\
\hline
\end{tabular}

For this multi-robot task allocation problem, we can get the final result as shown in Table 6.

Table 6. The final result

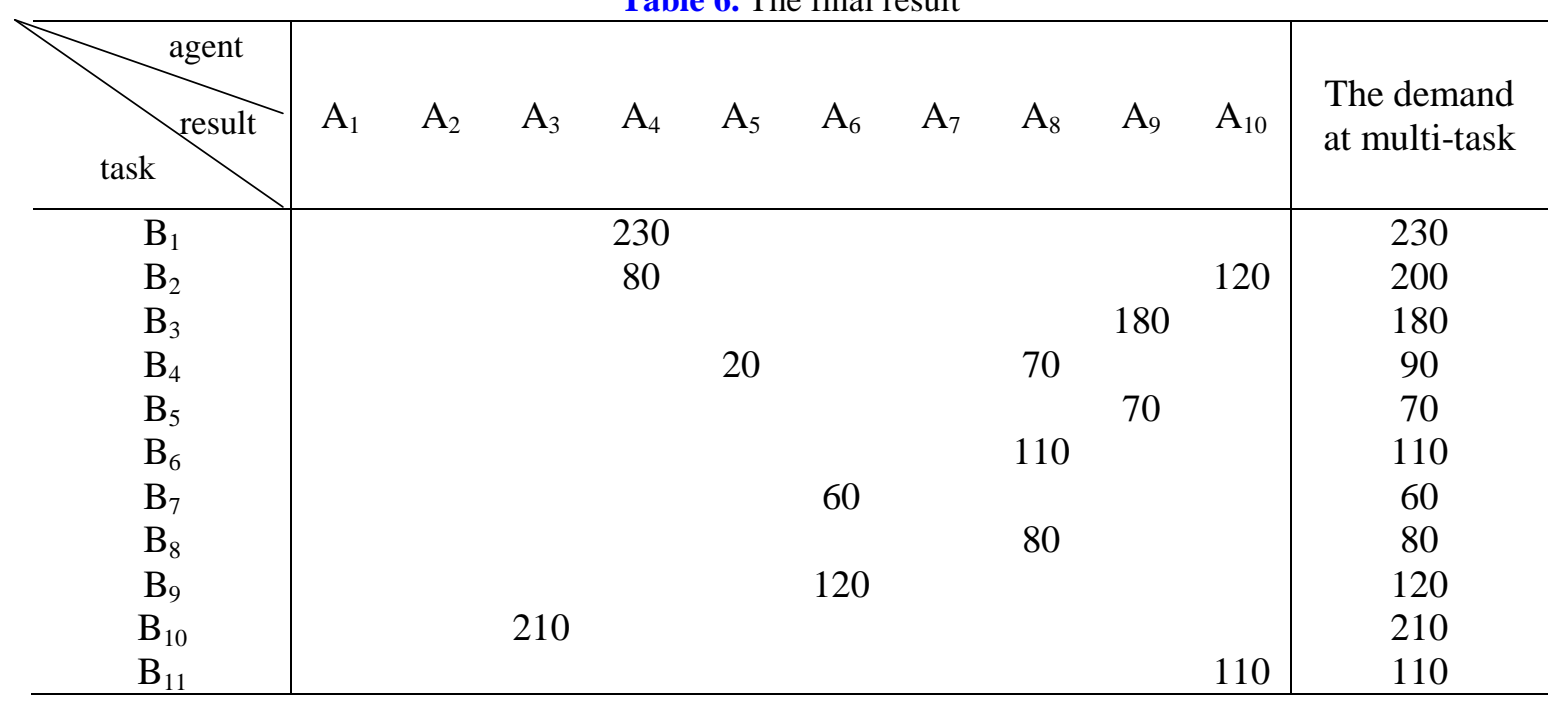




\begin{tabular}{|c|c|c|c|c|c|c|c|c|c|c|c|}
\hline $\begin{array}{l}\mathrm{B}_{12} \\
\mathrm{~B}_{13} \\
\mathrm{~B}_{14} \\
\mathrm{~B}_{15} \\
\mathrm{~B}_{16} \\
\mathrm{~B}_{17} \\
\mathrm{~B}_{18} \\
\mathrm{~B}_{19} \\
\mathrm{~B}_{20} \\
\end{array}$ & $\begin{array}{r}200 \\
90 \\
50\end{array}$ & 10 & 120 & & 270 & 90 & $\begin{array}{l}160 \\
190\end{array}$ & 80 & 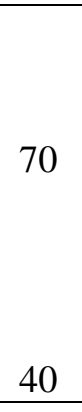 & 30 & $\begin{array}{c}150 \\
210 \\
360 \\
70 \\
50 \\
310 \\
160 \\
270 \\
160 \\
\end{array}$ \\
\hline $\begin{array}{l}\text { The supply } \\
\text { from } \\
\text { multi-agent }\end{array}$ & 340 & 320 & 330 & 310 & 290 & 270 & 350 & 340 & 360 & 290 & \\
\hline
\end{tabular}

The total benefit value is 1704.200 .

By comparing the modeling method in the paper and the traditional modeling method which only considers tasks in the least finished time from three respects including the amount of accomplish tasks, the power assumption of multi-robot and the time assumption of accomplish tasks. The results are shown in Fig. 4. and Fig. 5.

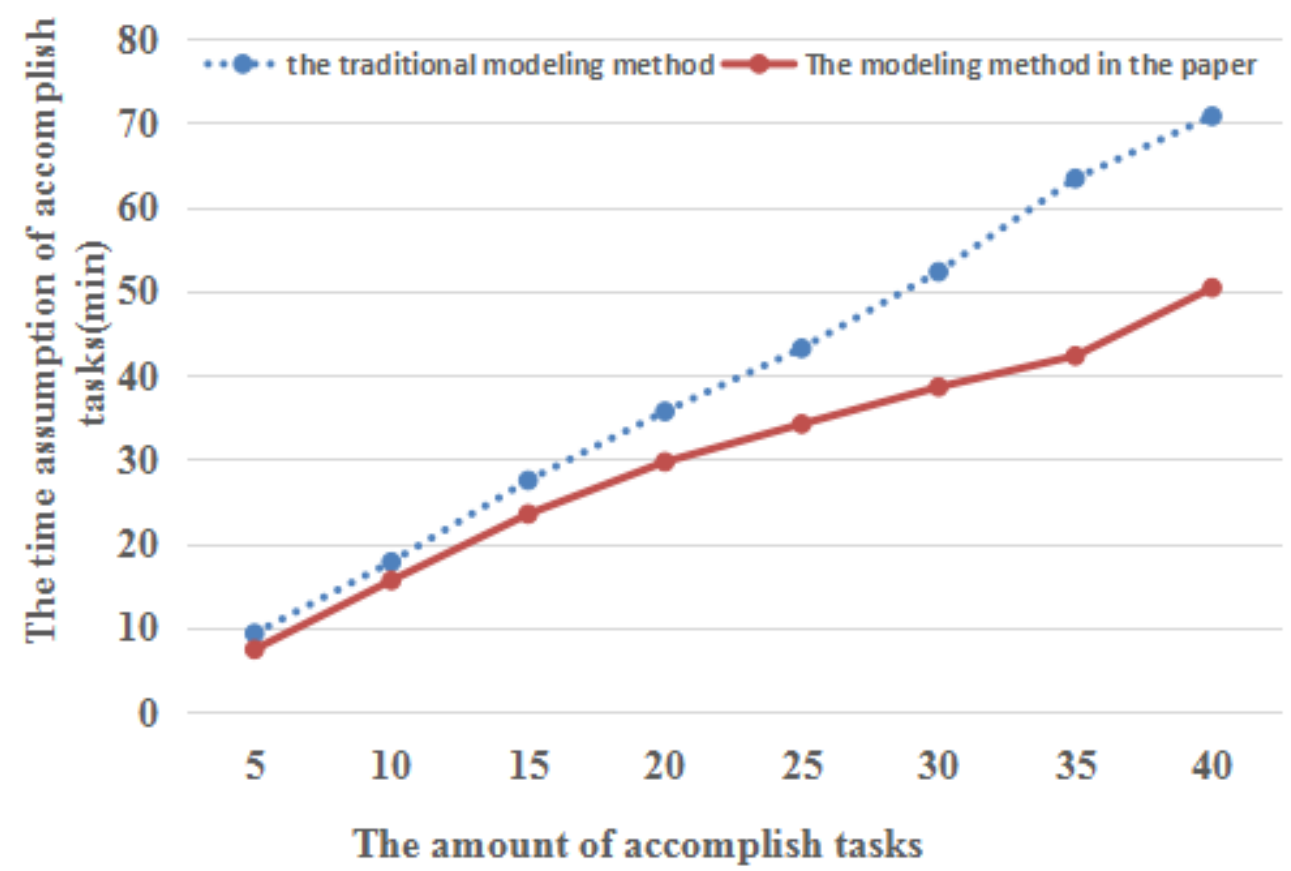

Fig. 4. The time assumption of accomplish tasks comparison 


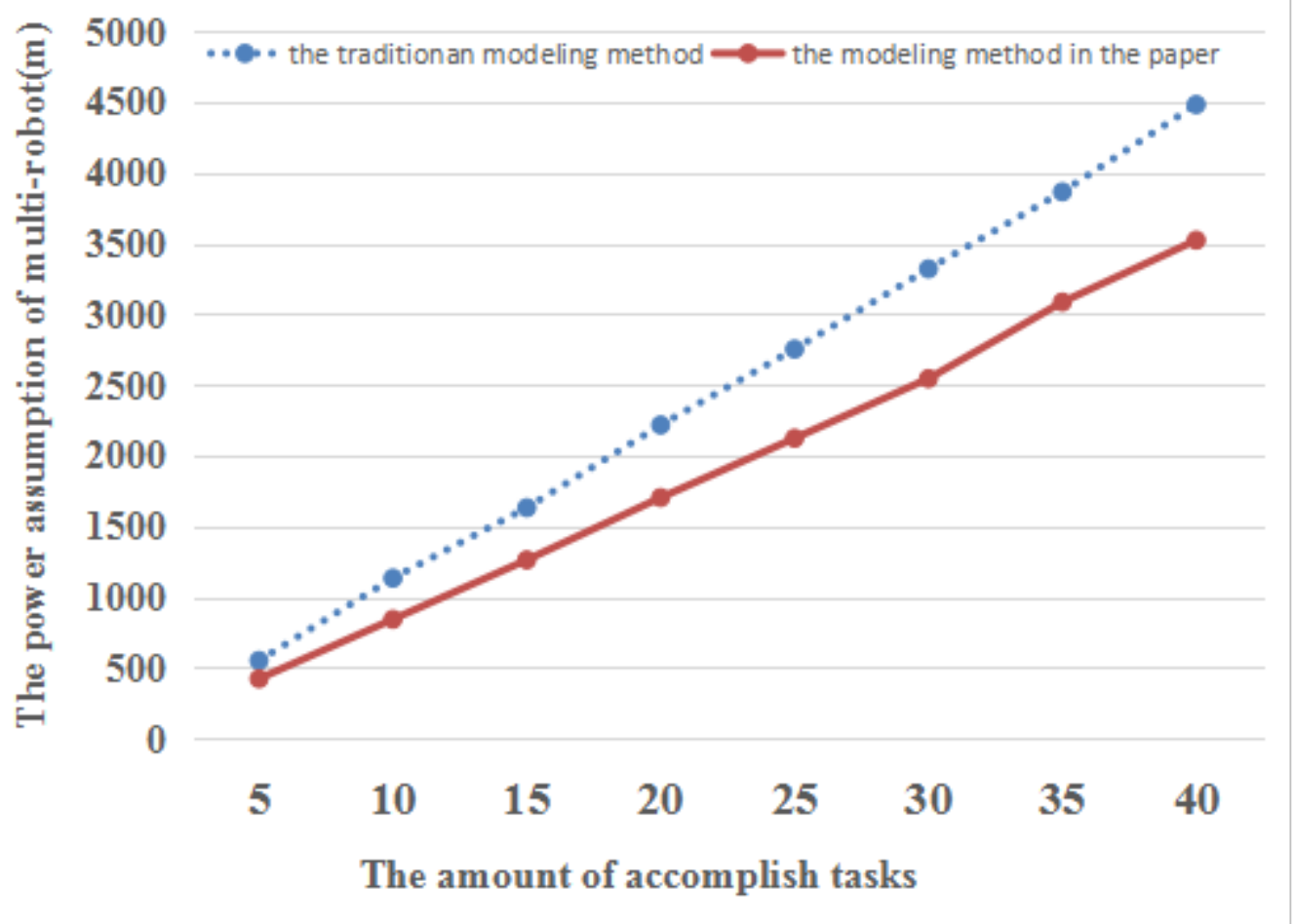

Fig. 5. The power assumption of multi-robot comparison

As can be seen from the above figures, the modeling method presented in this paper has obvious advantages over the traditional modeling method in both the time assumption of accomplish tasks and the power assumption of multi-robot under the premise of completing the same number of tasks. When the same 20 tasks are performed, the comparison results of the power assumption of multi-robot and the time assumption of accomplish tasks are shown in Table 7.

Table 7. Comparison results

\begin{tabular}{c|ccc}
\hline comparison results & $\begin{array}{c}\text { the amount of } \\
\text { accomplish tasks }\end{array}$ & $\begin{array}{c}\text { the power } \\
\text { assumption of } \\
\text { multi-agent( } \boldsymbol{m})\end{array}$ & $\begin{array}{c}\text { the time assumption of } \\
\text { accomplish tasks(min) }\end{array}$ \\
\hline $\begin{array}{c}\text { The traditional modeling } \\
\text { method }\end{array}$ & 18 & 2217.5 & 27.5 \\
$\begin{array}{c}\text { The modeling method in } \\
\text { the paper }\end{array}$ & 20 & 1704.2 & 29.7 \\
\hline
\end{tabular}

As shown in the table, according to the time assumption of accomplish tasks, the traditional modeling method is 35.7 minutes, faster than that of the modeling method in the paper. That is to say, using the modeling method in the paper can accomplish more tasks with the same time assumption. According to the power assumption of multi-robot, the traditional modeling method is $2217.5 \mathrm{~m}$, lower than that of the modeling method in the paper.

To sum up, the modeling method in the paper has better performance than the the traditional modeling method in some ways. 


\section{Conclusions and Prospects}

In the paper, a multi-robot task allocation model method of intelligent warehouse picking system based on table working method is proposed. First, the problem statement of the intelligent warehouse system based on multi-robot is given. Second, according to the given Intelligent warehouse system environment information, an integer programming formulation is constructed considering the time-bound tasks, the number of task allocation on an robot and the agent power consumption. Then, a new method is proposed to solve the problem of multi-robot task allocation. Finally, Simulation results show that the model method in the paper can improve the efficiency of task allocation.

Although we can get a new method to solve the problem of multi-robot task allocation, there are still many questions left over. In future work, the influence of some dynamic factors on the task time cost in real-world intelligent warehouse systems, such as damage to the logistics robot, the interaction between logistics robots, and stopping or turning of the robots during movement, will be considered. We will also continue to perform in-depth examination of the impact of dynamic uncertain factors on the task time cost.

\section{Acknowledgement}

This paper is supported by Major Project of Beijing Wuzi University(No.2017XJZD03),Youth Fund Project of Beijing Wuzi University (No.2018XJQN03), General Program of Science and Technology Development Project of Beijing Municipal Education Commission of China (No. KM201810037002),Scientific and Technological Cooperative Research Team Project of Beijing Wuzi University (No.2017GG05),Beijing Social Science Fund (No.16GLC064), Beijing Youth Top-notch Talent Plan of High-Creation Plan (No. 2017000026833ZK25), Canal Plan-Leading Talent Project of Beijing Tongzhou District, Young top-notch talent project of high level teacher team construction in Beijing municipal universities (No.CIT\&TCD201704059), Beijing excellent talents support project (No.2017000020124G063).

\section{References}

[1] Henn S, “Algorithms for on-line order batching in an order picking warehouse," Comput ers \& Operations Research, 39(11), 2549-2563, 2012. Article (CrossRef Link)

[2] Chiang $\mathrm{M} \mathrm{H}$, Lin C P, Chen M C, "The adaptive approach for storage assignment by mining data of warehouse management system for distribution centres,” Enterprise Inform ation Systems, 5(2), 219-234, 2011. Article (CrossRef Link)

[3] Enright J J, Wurman P R, "Optimization and coordinated autonomy in mobile fulfillment systems," in Proc. of AAAI Conference on Automated Action Planning for Autonomous Mobile Robots. pp. 33-38, 2011. Article (CrossRef Link)

[4] Wurman P R, Mountz M, Mountz M, "Coordinating hundreds of cooperative, autonomou s vehicles in warehouses,” Ai Magazine, 2019(1), 9-20, 2008. Article (CrossRef Link)

[5] Amanatiadis A A, Chatzichristofis S A, Charalampous K, et al., "A Multi-Objective Expl oration Strategy for Mobile Robots Under Operational Constraints,” IEEE Access, vol. 1, pp. 691-702, 2013. Article (CrossRef Link)

[6] Silva J E D, Sousa J B D, Pereira F L, "Dynamic Optimization Techniques for the Motion Coordination of Autonomous Vehicles," Coordination Control of Distributed Systems. Springer International Publishing, pp.19-26, 2015. Article (CrossRef Link) 
[7] Zadorozhny V, Lewis M., "Information Fusion Based on Collective Intelligence for Multi-robot Search and Rescue Missions," in Proc. of IEEE International Conference on Mobile Data Management, pp. 275-278, 2013. Article (CrossRef Link)

[8] Boysen N, Briskorn D, Emde S, "Parts-to-picker based order processing in a rack-moving mobile robots environment,” European Journal of Operational Research, 262(2), 550-562, 2017. Article (CrossRef Link)

[9] Yu J, "Intractability of Optimal Multirobot Path Planning on Planar Graphs," IEEE Robotics \& Automation Letters, 1(1), 33-40, 2016. Article (CrossRef Link)

[10] F Nzanywayingoma and Y Yang, "Effective Task Scheduling and Dynamic Resource Optimization based on Heuristic Algorithms in Cloud Computing Environment,” KSII.

[11] Transactions on Internet \& Information Systems, 11(12), pp. 5780-5802, December, 2017. Article (CrossRef Link)

[12] Khamis A, Hussein A, Elmogy A, "Multi-robot Task Allocation: A Review of the State-of-the-Art," Cooperative Robots and Sensor Networks, 31-51, 2015. Article (CrossRef Link)

[13] Tovey C, Lagoudakis M G, Jain S, et al., "The Generation of Bidding Rules for Auction-Based Robot Coordination,” Multi-Robot Systems. From Swarms to Intelligent Automata Volume III, 3-14, 2005. Article (CrossRef Link)

[14] Xu, Hao, Xing, Lining, Huang, La, "Regional Science and Technology Resource Allocation Optimization Based on Improved Genetic Algorithm," KSII Transactions on Internet \& Information Systems, 11(4), pp. 1972-1986, 2017. Article (CrossRef Link)

[15] E. Amiri, M. N. Dehkordi, "Dynamic data clustering by combining improved discrete artificial bee colony algorithm with fuzzy logic,” International Journal of Bio-Inspired Computation, vol. 12, no. 3, pp. 164-172, 2018. Article (CrossRef Link)

[16] K. E. Heraguemi, N. Kamel and H. Drias, "Multi-objective bat algorithm for mining numerical association rules,” International Journal of Bio-Inspired Computation, vol. 11, no. 4, pp. 239-248, 2018. Article (CrossRef Link)

[17] M. Abdel-Baset, Y. Zhou and M. Ismail, “An improved cuckoo search algorithm for integer programming problems,” International Journal of Computing Science and Mathematics, vol. 9, no. 1, pp. 66-81, 2018. Article (CrossRef Link)

[18] Z. Cui, B. Sun, G. Wang, Y. Xue and J. Chen, “A novel oriented cuckoo search algorithm to improve DV-Hop performance for cyber--physical systems,” Journal of Parallel and Distributed Computing, vol. 103, pp. 42-52, 2017. Article (CrossRef Link)

[19] Hübner A, Kuhn H, Kühn S, “An efficient algorithm for capacitated assortment planning with stochastic demand and substitution,” European Journal of Operational Research, 250(2), pp.505-520, 2016. Article (CrossRef Link)

[20] M. Sajid, Z. Raza and M. Shahid, "Hybrid bio-inspired scheduling algorithms for batch of tasks on heterogeneous computing system,” International Journal of Bio-Inspired Computation, vol. 11, no. 3, pp. 135-148, 2018. Article (CrossRef Link)

[21] G. Duan, L. Chen, Y. Li and R. He, "Optimisation on empty trains distribution with time window in heavy haul railway," International Journal of Computing Science and Mathematics, vol. 9, no. 3, pp. 273-286, 2018. Article (CrossRef Link)

[22] X. Cai, H. Wang, Z. Cui, J. Cai, Y. Xue and L. Wang, "Bat algorithm with triangle-flipping strategy for numerical optimization,” International Journal of Machine Learning and Cybernetics, vol. 9, no. 2, pp. 199-215, 2018. Article (CrossRef Link)

[23] R. P. Tripathi, M. Kaur, “A linear time-dependent deteriorating inventory model with linearly time-dependent demand rate and inflation,” International Journal of Computing Science and Mathematics, vol. 9, no. 4, pp. 352-364, 2018. Article (CrossRef Link)

[24] Faigl J, Kulich M, Preucil L, "Goal assignment using distance cost in multi-robot exploration," in Proc. of Intelligent Robots and Systems (IROS), 2012 IEEE/RSJ International Conference on. IEEE, pp. 3741-3746, 2012. Article (CrossRef Link) 
[25] Beifang Bao, Yu Yang, Qian Chen, et al., "Task allocation optimization in collaborative customized product development based on double-population adaptive genetic algorithm," Journal of Intelligent Manufacturing, 27(5), 1097-1110, 2016. Article (CrossRef Link)

[26] Y. Cao, Z. Ding, F. Xue and X. Rong, "An improved twin support vector machine based on multi-objective cuckoo search for software defect prediction,” International Journal of Bio-Inspired Computation, vol. 11, no. 4, pp. 282-291, 2018. Article (CrossRef Link)

[27] Z. Cui, J. Zhang, Y. Wang, Y. Cao, X. Cai, W. Zhang and J. Chen, "A pigeon-inspired optimization algorithm for many-objective optimization problems," SCIENCE CHINA Technological Sciences, 2019. Article (CrossRef Link)

[28] G. Saranya, H. K. Nehemiah and A. Kannan, "Hybrid particle swarm optimisation with mutation for code smell detection,” International Journal of Bio-Inspired Computation, vol. 12, no. 3, pp. 186-195, 2018. Article (CrossRef Link)

[29] P. K. Pandey, "An efficient numerical method for the solution of third order boundary value problem in ordinary differential equations," International Journal of Computing Science and Mathematics, vol. 9, no. 2, pp. 171-180, 2018. Article (CrossRef Link)

[30] W. Arloff, K. R. Schmitt and L. J. Venstrom, “A parameter estimation method for stiff ordinary differential equations using particle swarm optimisation,” International Journal of Computing Science and Mathematics, vol. 9, no. 5, pp. 419-432, 2018. Article (CrossRef Link)

[31] R. Xiao, Y. Wang, "Labour division in swarm intelligence for allocation problems: a survey," International Journal of Bio-Inspired Computation, vol. 12, no. 2, pp. 71-86, 2018. Article (CrossRef Link)

[32] S. Sindhu, S. Mukherjee, “An evolutionary approach to schedule deadline constrained bag of tasks in a cloud,” International Journal of Bio-Inspired Computation, vol. 11, no. 4, pp. 229-238, 2018. Article (CrossRef Link)

[33] H. Wang, W. Wang, X. Zhou, H. Sun, J. Zhao, X. Yu and Z. Cui, "Firefly algorithm with neighborhood attraction,” Information Sciences, vol. 382-383, pp. 374-387, 2017.

Article (CrossRef Link)

[34] X. Cai, X. Gao and Y. Xue, "Improved bat algorithm with optimal forage strategy and random disturbance strategy," International Journal of Bio-Inspired Computation, vol. 8, no. 4, pp. 205-214, 2016. Article (CrossRef Link)

[35] G. Yu, Y. Feng, “Improving firefly algorithm using hybrid strategies,” International Journal of Computing Science and Mathematics, vol. 9, no. 2, pp. 163-170, 2018. Article (CrossRef Link)

[36] L. Lv, T. Fan, Q. Li, Z. Sun and L. Xu, "Object tracking with improved firefly algorithm," International Journal of Computing Science and Mathematics, vol. 9, no. 3, pp. 219-231, 2018. Article (CrossRef Link)

[37] M. Zhang, H. Wang, Z. Cui and J. Chen, "Hybrid multi-objective cuckoo search with dynamical local search,” Memetic Computing, vol. 10, no. 2, pp. 199-208, 2018. Article (CrossRef Link)

[38] Z. Cui, F. Li and W. Zhang, "Bat algorithm with principal component analysis," International Journal of Machine Learning and Cybernetics, vol. 10, no. 3, pp. 603-622, 2019. Article (CrossRef Link)

[39] Y. Wang, P. Wang, J. Zhang, Z. Cui, X. Cai, W. Zhang and J. Chen, “A Novel Bat Algorithm with Multiple Strategies Coupling for Numerical Optimization,” Mathematics, vol. 7, no. 2, pp. 135, 2019. Article (CrossRef Link)

[40] Z. Cui, Y. Cao, X. Cai, J. Cai and J. Chen, “Optimal LEACH protocol with modified bat algorithm for big data sensing systems in Internet of Things," Journal of Parallel and Distributed Computing, vol. 132, pp. 217-229, 2019. Article (CrossRef Link)

[41] Z. Cui, F. Xue, X. Cai, Y. Cao, G. Wang and J. Chen, "Detection of malicious code variants based on deep learning,” IEEE Transactions on Industrial Informatics, vol. 14, no. 7, pp. 3187-3196, 2018. Article (CrossRef Link)

[42] Gheraibia Y, Djafri K, Krimou H, “Ant colony algorithm for automotive safety integrity level allocation,” Applied Intelligence, vol. 48, no. 3, pp. 555-569, 2018. Article (CrossRef Link) 
[43] Nedjah N, Mendonc,A R M D, Mourelle L D M, "PSO-based Distributed Algorithm for Dynamic Task Allocation in a Robotic Swarm,” Procedia Computer Science, pp. 326-335, 2015. Article (CrossRef Link)

[44] Neshat M, Adeli A, Sepidnam G, et al., "A Review of Artificial Fish Swarm Optimization Methods and Applications,” International Journal on Smart Sensing \& Intelligent Systems, vol. 5, no. 1, pp. 107-148, 2012. Article (CrossRef Link)

[45] Lozenguez G, Adouane L, Beynier A, et al., "Punctual versus continuous auction coordination for multi-robot and multi-task topological navigation,” Autonomous Robots, 40(4), 599-613, 2016. Article (CrossRef Link)

[46] Heap B, Pagnucco M, "Repeated Sequential Single-Cluster Auctions with Dynamic Tasks for Multi-Robot Task Allocation with Pickup and Delivery," in Proc. of German Conference on Multiagent System Technologies. Springer Berlin Heidelberg, 87-100, 2013. Article (CrossRef Link)

[47] Zlot R, Stentz A, Dias M B, et al., "Multi-robot exploration controlled by a market eco nomy," in Proc. of IEEE International Conference on Robotics and Automation, 2002. Pro ceedings. ICRA, pp.3016-3023, 2002. Article (CrossRef Link)

[48] Elango M, Nachiappan S, Tiwari M K, "Balancing task allocation in multi-robot systems using K-means clustering and auction based mechanisms," Expert Systems with Applicati ons, 38(6), 6486-6491, 2011. Article (CrossRef Link)

[49] Nagarajan T, Thondiyath A, "Heuristic based Task Allocation Algorithm for Multiple Ro bots Using Agents,” Procedia Engineering, 64, 844-853, 2013. Article (CrossRef Link)

[50] Li Y-de, "Model and algorithm for cartonization and slotting optimization simultaneously in wave-picking zone-based system," Syst Eng Theory Pract, 33(5), 1269-1276, 2013. Article (CrossRef Link)

[51] Wurman P R, Mountz M, Mountz M, "Coordinating hundreds of cooperative, autonomou $\mathrm{s}$ vehicles in warehouses," in Proc. of National Conference on Innovative Applications of Artificial Intelligence. AAAI Press, 29(1), 9, 2008. Article (CrossRef Link)

[52] Enright J J, Wurman P R, "Optimization and coordinated autonomy in mobile fulfillment systems," in Proc. of AAAI Conference on Automated Action Planning for Autonomous Mobile Robots. AAAI Press, 2011. Article (CrossRef Link)

[53] Luo L, Chakraborty N, Sycara K, "Distributed Algorithms for Multirobot Task Assignme nt With Task Deadline Constraints,” IEEE Transactions on Automation Science \& Engine ering, 12(3), 876-888, 2015. Article (CrossRef Link)

[54] Liu Ke, Guo Xiao-he,Zhou Ji-qiang;Lu Yongle, “Multi-task allocation problem research b ased on multi-agent," Application Research of Computers, 31(7), 1980-1983, 2014. Article (CrossRef Link) 


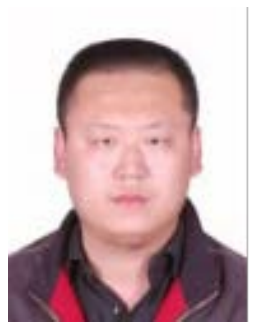

Fei Xue is a Lecturer at the School of Information, Beijing Wuzi University. He received the Ph.D. degree in Computer Science and Technology from Beijing University of Technology, China, in 2016. His current research interests are in the areas of swarm intelligence optimization, deep learning and network security. He has published about 30 papers in academic journals and conferences.

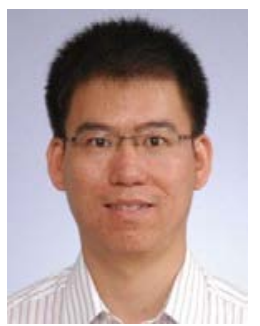

Hengliang Tang is an Associate professor of Beijing Wuzi University, Beijing, China. He received his Ph.D. degree from Beijing University of Technology in 2011. His research interest covers internet of things, virtual reality and pattern recognition.

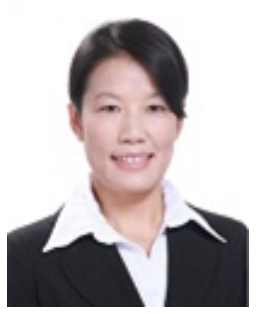

Qinghua Su is an Associate professor of Beijing Wuzi University, Beijing, China. She received her Ph.D. degree from Beijing University of Aeronautics and Astronautics in 2014. Her research interest covers internet of things, machine learning and pattern recognition.

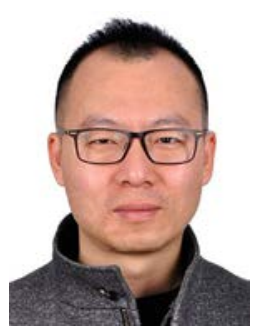

Tao Liu is a Lecturer of Beijing Wuzi University, Beijing, China. He received his Ph.D. degree from University of Science and Technology Beijing in 2011. His research interest covers discrete-time system and sliding mode control. 